\title{
Retención y efecto anticariogénico de los selladores en molares primarios. Ensayo clínico controlado
}

Jesús Alberto Luengo-J ${ }^{1}$

Sarahí Mena Martínez $z^{2}$

Luz Elena Carlos Medrano ${ }^{3}$

Iovanna Toscano García ${ }^{4}$

\section{Resumen}

Objetivo: Evaluar la retención y efecto anticariogénico de los selladores en molares primarios. Material y Métodos: Se realizó un ensayo clínico, controlado, ciego simple, con diseño de boca dividida, en 320 segundos molares primarios libres de caries de 80 niños con edades entre 3 y 5 años. Fueron sellados con vidrio ionomérico Ketac Molar ${ }^{\circledR}$ $3 \mathrm{M}$ segundos molares derechos y con sellador de resina Clinpro® $3 \mathrm{M}$ segundos molares izquierdos. Después de doce meses se evaluó la retención y la incidencia de caries. Los datos se procesaron con el programa SPSS V-19. Se utilizó la prueba Chi cuadrado y Test de Fisher. Resultados: El grupo control obtuvo $20 \%$ de retención total y el experimental 13.3\%. El sellador Clinpro® mostró 28.6\% de pérdida, y el sellador Ketac Molar® 32\%. Dentro del grupo experimental ningún molar presentó lesiones, mientras que el grupo control hubo un $16.3 \%$ de incidencia de caries, estas diferencias fueron estadísticamente significativas $(\mathrm{p}<0.05)$. Conclusión: La retención del sellador de resina fue superior a la del cemento de ionómero de vidrio luego de 1 año. La retención de los selladores en los dientes mandibulares fue superior a la de los dientes maxilares. No hubo incidencia de lesiones de caries dental en el grupo de molares sellados con pérdida del ionómero de vidrio, contrario al grupo que recibió el sellador a base de resina donde se presentaron 7 casos de la enfermedad.

Palabras clave: Selladores, fisuras, cemento de ionómero de vidrio, resinas compuestas.

Artigo Original

\section{Retenção e efeito anticariogênico de selantes em molares decíduos. Ensaio clínico controlado}

\footnotetext{
Abstrato

rial e Métodos: Foi realizado um estudo clínico

Objetivo: Avaliar a retenção e o efeito anticariocontrolado, simples-cego, com um desenho em boca dividida envolvendo 320 segundos molagênico de selantes em molares decíduos. Materes decíduos livres de cárie em 80 crianças de 3 e

${ }^{1}$ Doctor Ciencias Odontológicas. Docente - Investigador Especialidad Odontopediatría. Universidad Autónoma de Zacatecas, México. jluengofereira@gmail.com ${ }^{2}$ Médico Cirujano Dentista. Estudiante Especialidad Odontopediatría. Universidad Autónoma de Zacatecas, México. cdsarahimena@hotmail.com

${ }^{3}$ Maestra Ciencias. Docente - Investigador Especialidad Odontopediatría. Universidad Autónoma de Zacatecas, México. zacatecasss22@gmail.com

${ }^{4}$ Especialista Cirugía Maxilofacial. Docente - Investigador Especialidad Odontopediatría. Universidad Autónoma de Zacatecas, México. iotoscanogarcia@yahoo.com.mx
} 
5 anos. Os segundos molares direitos foram selados com ionômero de vidro Ketac Molar® 3M e os esquerdos com selante resinoso Climpro® 3M. Após doze meses, se avaliou a retenção e a incidência de cárie. Os dados foram processados através do programa SPSS V-19. Foram utilizados os testes do Qui-quadrado e de Fisher. Resultados: $O$ grupo controle teve $20 \%$ de retenção e o experimental 13,3\%. O selante Climpro® teve perda de $28,6 \%$ e o Ketac Molar $® 32 \%$. Nenhum molar do grupo experimental apresentou lesões de cárie enquanto no grupo controle 16,3\% desenvolveram cárie. Conclusão: Após um ano, a retenção do selante resinoso foi maior do que a do ionômero de vidro. Molares tratados com Climpro® e que apresentaram perda do selante desenvolveram a doença.

Palavras chave: Selantes de fóssulas e fissuras, cimentos de ionômero de vidro, resinas compostas.

Original article

\section{Retention and anti-cariogenic effect of sealants in primary molars. Controlled trial}

\begin{abstract}
Objective: Evaluate retention and anti-cariogenic effect of sealants in primary molars. Material and Methods: A controlled, single -blind, split-mouth design, 320 seconds primary molars caries free of 80 healthy children aged 3 and 5 years clinical trial was conducted. They were sealed with glass ionomer Ketac Molar® 3M second molars rights and resin sealant $3 \mathrm{M} \AA$ Clinpro left second molar. After twelve months the retention and caries incidence was evaluated. Data were processed with SPSS V-19 program. The Chi square test and Fisher test was used. Results: The control group scored $20 \%$ overall retention and experimental $13.3 \%$. The Clinpro® sealant showed $28.6 \%$ loss, and sealer Ketac Mo$\operatorname{lar}{ }^{\circledR} 32 \%$. Within the experimental molar presents no lesions, whereas the control group there was a $16.3 \%$ incidence of caries, these differences were statistically significant $(\mathrm{p}<0.05)$. Conclusion: The resin sealant retention was higher than the glass ionomer cement after 1 year. Retention
\end{abstract}

of sealants on the mandibular teeth was higher than that of the maxillary teeth. There was no incidence of dental caries lesions in the group of molars sealed with glass ionomer loss, contrary to the group receiving resin-based sealant which 7 cases of the disease were presented.

Keywords: Seals, fissures, glass ionomer cement, composites resin.

\section{Introducción}

La salud bucal participa en funciones vitales como la alimentación, la comunicación y el afecto; por lo tanto, está relacionada con el bienestar y la calidad de vida desde el punto de vista funcional, psicosocial y económico ${ }^{1}$. Las enfermedades bucales afectan entre 60 y $90 \%$ de la población mundial, sin distingo de edad, sexo, condición social y lugar de residencia; siendo la caries dental la principal patología 2,3,4.

Sin embargo, es necesario comprender que la caries dental es un proceso dinámico, localizado 
en los tejidos duros del diente, producida por un desequilibrio entre la superficie dental y el fluido de la placa circundante ${ }^{5}$. Por los que al establecerse la microbiota cariogénica, los azucares disponibles en la placa favorecen la producción de ácidos bacterianos que desmineralizan al diente causando cambios estructurales anatomopatológicos en el tejido dental duro ${ }^{6}$. Este proceso carioso puede ser reversible o irreversible; activo de progreso rápido o lento, e inactivo o detenido; conducido por la actividad de la placa y por lo tanto la modificación de la misma conlleva a la modificación del proceso $^{7}$.

La enfermedad aparece principalmente en las fosas y fisuras de las superficies oclusales de molares primarios y permanentes ${ }^{8}$ debido a la compleja morfología que éstas superficies presentan, convirtiéndolas en zonas de difícil acceso para la auto-limpieza o el cepillado dental convencional; y de mayor susceptibilidad al acumulo de placa dental, produciendo así, que el esmalte no reciba los mismos niveles de flúor y de antimicrobianos, en comparación a las superficies lisas ${ }^{9}$.

De igual manera, la acumulación de placa y susceptibilidad a la caries son mayores durante la erupción de los molares, aunado a la susceptibilidad de cada individuo, hacen que estas superficies sean vulnerables para el inicio temprano y la rápida progresión de la caries ${ }^{10}$.

Una de las estrategias que se ha implementado para prevenir la aparición y controlar la progresión de las lesiones cariosas en las superficies oclusales, es el uso de selladores de puntos y fisuras $^{11}$. Estos materiales previenen el desarrollo de las bacterias cariogénicas, al formar una capa protectora de adhesión micro-mecánica a los prismas del esmalte dental, suprimiendo así el acceso de los microorganismos a las zonas susceptibles ${ }^{12}$.
Se conocen dos tipos de materiales empleados como selladores: de resina, son los de primera elección; y de ionómero de vidrio, considerados como una alternativa en los casos donde el control de la humedad se encuentra limitado ${ }^{10,12}$, además, liberan iones de fluoruro al esmalte adyacente y absorben fluoruro de otras fuentes, como dentífricos y enjuagues bucales, comportándose en la cavidad oral, como dispositivos de recarga y de liberación progresiva de fluoruro ${ }^{13}$.

A pesar de lo expuesto, se ha indicado que la efectividad de la aplicación de los sellantes de fosas y fisuras, para prevenir caries dental en los dientes posteriores de niños con alto riesgo a desarrollar la enfermedad, se encuentra relacionada con la retención del material a largo plazo en su sitio de aplicación ${ }^{14,15}$; ya que, cuando el sellador se pierde o la fisura que estaba sellada queda parcialmente descubierta, los fluidos orales pueden migrar a la fisura y/o debajo del sellador, y así posiblemente interactuar con las bacterias de la placa dental, produciendo que el proceso carioso pase a un estado activo ${ }^{16}$.

La evidencia científica sustenta el uso de estos materiales como una medida efectiva para prevenir el desarrollo de lesiones de caries dental. No obstante en la actualidad, los estudios acerca de cuál material es el más efectivo resultan contradictorios. Beauchamp y col. ${ }^{12}$, indican que la disminución en la incidencia de caries dental después de la colocación de un sellador va desde un $86 \%$ al año, $78.6 \%$ a los 2 años y $56.6 \%$ a los 4 años.

Salar y col. ${ }^{17}$, en un ensayo clínico, aleatorio, compararon tres tipos de sellantes: uno resinoso, sellante resinoso que libera fluoruro y otro de vidrio ionomérico. Este estudio demostró que los sellantes resinosos que liberaban fluoruros inhiben la desmineralización del esmalte 
adyacente al material, pero menos que aquellos de vidrio ionomérico. Trairatvorakul y $\mathrm{col}^{18}{ }^{18}$, reportan que los selladores de ionómero de vidrio son capaces de reducir la incidencia de lesiones cariosas $0.5 \mathrm{~mm}$ en las adyacencias de los materiales. Kantovitz y col. ${ }^{19}$, indican que los selladores resinosos no previenen la desmineralización del esmalte, contrario a los de vidrio ionomérico, los cuales muestran una mayor capacidad de liberación de fluoruros.

Otro estudio realizado por Beiruti y col. ${ }^{20}$, sobre el efecto preventivo de los sellantes, indica que luego de 5 años de evaluación, el $88 \%$ y el $86 \%$ de los sellantes de resina y los de vidrio ionómero (aplicados con la técnica TRA), se habían perdido respectivamente. Así mismo, posterior a los 2 y 3 años de la pérdida de material, las lesiones de caries de dentina aparecieron en un $13 \%$ en el grupo de sellantes de resina y $3 \%$ en el grupo de sellantes de vidrio ionomérico. Los autores concluyeron, en que el sellante de vidrio ionomérico parece tener 4 veces más oportunidad de prevenir el desarrollo de caries en fosas y fisuras que los sellantes resinosos. Sin embargo, no existe evidencia suficiente sobre que material es superior al otro ${ }^{21}$.

Las controversias en los estudios descritos anteriormente, de cuál es el mejor material para ser empleado como sellador, motivaron el propósito de la investigación la cual fue, evaluar la retención y el efecto anticariogénico de los selladores aplicados en molares primarios.

\section{Material y métodos}

La muestra estuvo conformada por 320 segundos molares primarios, seleccionados de $80 \mathrm{ni}-$ ños con edades entre los 3 y 5 años, estudiantes de preescolar del municipio Calera de Víctor Rosales, Zacatecas, México. Se incluyeron, pa- cientes con los cuatro segundos molares primarios totalmente erupcionados, con la superficie oclusal totalmente visible y sin lesión de caries según el Sistema Internacional para la Detección y Evaluación de Caries Dental (ICDAS II) ${ }^{22}$. Se excluyeron, pacientes con segundos molares primarios parcialmente erupcionados, algún tipo de material de restauración, lesiones cariosas según ICDAS II $^{22}$, enfermedad periodontal, fluorosis, hipoplasia de esmalte, pacientes no colaboradores o con enfermedad sistémica. El representante legal y el niño recibieron un informe detallado del estudio y firmaron un consentimiento para autorizar su participación en el estudio, de acuerdo con los principios de la declaración de Helsinki²3.

Diseño Experimental: Se realizó un ensayo clínico, controlado, ciego simple, con diseño de boca dividida y 2 tipos de tratamientos. Los pacientes recibieron ambos selladores. Desde el inicio del estudio los molares fueron asignados a cada tratamiento, experimental: dientes 55-85 (160 segundos molares) recibieron sellador de vidrio ionomérico Ketac Molar Easymix ${ }^{\circledR} 3 \mathrm{M}$ ESPE; control: dientes 65-75 (160 segundos molares) recibieron sellador a base de resina Clinpro® $3 \mathrm{M}$ ESPE.

Tamaño Muestral: Se realizó un muestreo no probabilístico por conveniencia de 80 niños con 320 órganos dentales, los cuales cumplían con los criterios de inclusión.

Evaluación clínica basal: inicialmente a los pacientes se les realizó una historia médico-odontológica y cepillado dental. Las unidades de observación fueron evaluadas según los criterios de ICDAS II $^{22}$ por un odontólogo calibrado $(K=0.86)$, que no intervino en la aplicación de los tratamientos, empleando lámpara frontal de luz LED, un espejo bucal plano $\mathrm{N}^{\circ} 5$, una sonda de 
la O.M.S., y aire comprimido de la jeringa triple (equipo portátil RCL®).

\section{Procedimiento para el sellado de las lesiones:}

Los pacientes fueron atendidos en el interior del preescolar, dentro de un salón que contaba con adecuada iluminación, acostando a los niños sobre mesitas de trabajo. Dos odontólogos entrenados, realizaron todos los procedimientos. La manipulación de los materiales fue realizada según las indicaciones del fabricante, por otros dos odontólogos, que sirvieron de cuarta mano. Todos los pacientes recibieron ambos materiales, los selladores de resina en los molares 65-75, y los de vidrio ionomérico en 55-85. Igualmente, se dieron indicaciones de no ingerir ningún alimento una hora después de recibir el tratamiento.

Tratamiento experimental: selladores de vidrio ionomérico: Los molares seleccionados segundo molar temporal superior derecho (55) y segundo molar temporal inferior derecho (85), se les aplicó el sellador de vidrio ionomérico (3M ESPE Ketac Molar Easymix® St Paul MN). El procedimiento fue: remoción del biofilm con cepillado dental, aislamiento relativo con rollos de algodón, secado de la superficie con torundas de algodón y acondicionada con acido poliacrílico durante 10 segundos, seguido del lavado con agua y secado de la superficie. La técnica de presión digital fue utilizada para condensar el material dentro de las fosas y fisuras, durante 30 segundos realizando movimientos en sentido mesio-distal y vestibulo-lingual y/o palatino, se removieron los excesos del material con una cucharita de dentina. Después de un endurecimiento inicial, la oclusión fue valorada con papel articular (Prehma, Medeco Miami, FL). Una capa de vaselina (100\% Petrolato, Vaseline $\AA)$, fué colocada sobre el material para prevenir la deshidratación.
Tratamiento control: selladores de resina: Los molares seleccionados, segundo molar temporal superior izquierdo (65) y segundo molar temporal inferior izquierdo (75), recibieron la aplicación del sellador de resina (3M ESPE Clinpro® St Paul MN). Bajo aislamiento absoluto con grapas Hu-Friedy (Hu-Friedy Chicago, IL USA) y diques de hule Dental Dam Non Latex (Dental Dam Nic Tone ${ }^{\circledR)}$, profilaxis con piedra pómez (EZ-PUMICE, Products Fesenko), lavado y secado de la superficie con la jeringa triple, técnica de grabado con ácido fosfórico al 35\% (Scotchbond $® 3$ M ESPE St Paul MN) durante 15 segundos, se lavó por 30 segundos y se secó con aire de la jeringa triple, se removieron con succión los residuos de agua, se aplicó el sellador en las fosas y fisuras, se fotocura el material durante 40 segundos (lámpara de luz ultravioleta QHL75 Curing Light巴 Dentsply® de 450 a 525 nanómetros de longitud de onda), se retira el aislamiento, la oclusión se evaluó con papel articular (Prehma, Medeco Miami, FL).

Evaluación clínica del tratamiento: Después de 12 meses se evaluaron los tratamientos, realizada por el mismo examinador que efectuó la evaluación clínica basal (bajo las mismas condiciones), determinando la retención del material y la incidencia de lesiones de caries dental. Para evaluar la efectividad de los tratamientos se registró la retención del sellador de acuerdo a los criterios de García-Godoy ${ }^{24}$ (Tabla 1), considerándose solo dos situaciones: tratamiento exitoso (sellador con retención total) y tratamiento defectuoso (sellador con retención parcial y pérdida completa). Las fisuras con pérdida completa del material fueron examinadas para la incidencia de caries según los criterios ICDAS II ${ }^{22}$.

Análisis estadístico: El procesamiento estadístico se realizó con la aplicación SPSS-Windows V19.0 (SPSS, Inc, Chicago IL). Para identificar 
las diferencias entre los tipos de tratamiento se realizaron los siguientes procedimientos a un nivel de significancia del 5\%: Pruebas de Bondad de Ajuste con la distribución de Chi Cuadrado, para comparar la retención según la ubicación de los molares y por grupo de tratamiento. Test de Fisher para contrastar la incidencia de lesiones de caries dental entre los grupos de unidades experimentales y controles con fracaso del tratamiento.

\section{Resultados}

De 320 segundos molares temporales incluidos en el estudio, 300 lograron ser evaluados posterior a doce meses correspondientes a 75 niños, 45 del sexo femenino $(60 \%)$ y 30 del sexo masculino (40\%). Mientras que 20 molares $(6.25 \%)$ de 5 pacientes $(6.25 \%)$ no lograron ser evaluados en este periodo de tiempo, debido a que no asistieron a la escuela durante los días de evaluación.

En cuanto a la retención del material en los molares del grupo control (segundos molares temporales superior e inferior izquierdos) (Tabla 2), los molares superiores tuvieron $9.3 \%$ de retención completa del sellador, y los inferiores el $30.6 \%$. Estas diferencias fueron significativas $(p<0.05)$. Así mismo, en los molares superiores el $61.3 \%$ tuvieron retención parcial y $29.3 \%$ pérdida completa del material; mientras que en los molares inferiores el $41.3 \%$ tuvieron retención parcial y $28 \%$ perdida completa del sellador. El porcentaje total de fracasos fue de $90.6 \%$ en los superiores y de $69.3 \%$ en los inferiores. No hubo diferencias significativas en el fracaso del tratamiento según el diente tratado ( $p>0.05)$. Las diferencias de retención de los selladores en los molares temporales superiores e infe- riores del lado izquierdo, fueron significativas $(\mathrm{p}<0.05)$.

En el grupo experimental (segundos molares temporales superior e inferior derechos) (Tabla 3), los molares superiores obtuvieron $10.6 \%$ de retención completa del sellador y los inferiores $16 \%$. Conforme a la retención parcial y pérdida completa del material los molares superiores obtuvieron $52 \%$ y $37.3 \%$ respectivamente; mientras que lo observado en los molares inferiores fue de $57.3 \%$ y $26.6 \%$. El porcentaje de fracasos fue de $89.3 \%$ en los superiores y $84 \%$ en los inferiores. No hubo diferencias significativas en las categorías de retención del presente grupo de tratamiento $(\mathrm{p}>0.05)$.

En la evaluación de la retención de los selladores de acuerdo al grupo de tratamiento (Tabla 4), el grupo control obtuvo $20 \%$ de retención completa y el grupo experimental $13.3 \%$. De igual manera el sellador de resina Clinpro® mostró menor porcentaje de perdida con el $28.6 \%$, mientras que para el sellador de ionómero Ketac Molar® fue de $32 \%$. Estas diferencias no fueron estadísticamente significativas ( $p>0.05)$.

La incidencia de lesiones de caries dental en los segundos molares temporales con pérdida completa del material sellador después de 12 meses (Tabla 5), en el grupo experimental ninguno de los dientes tratados presentó lesión de caries donde se perdió por completo el sellante, el 100\% de los molares se mantuvieron sanos. No obstante, en el grupo control 16.3\% de los molares desarrollaron lesiones de caries y el $83.7 \%$ se mantuvieron sanos. La incidencia general de lesiones cariosas fue del 7.7\%. Los resultados sobre la incidencia de caries en los molares de los grupos de tratamiento mostraron diferencias significativas $(\mathrm{p}<0.05)$. 
Tabla 1. Criterios empleados para la retención de los sellantes, según García-Godoy ${ }^{24}$

\begin{tabular}{|c|}
\hline Retención del Sellante \\
\hline Retención Total: el sellante cubre todas las fosas y fisuras \\
\hline Retención Parcial: el sellante cubre parcialmente las fosas y fisuras \\
\hline Perdido: pérdida completa del sellante en todas las áreas de la superficie \\
\hline
\end{tabular}

Tabla 2. Retención de los selladores de resina según el diente sellado

\begin{tabular}{|c|c|c|c|c|c|c|c|c|c|c|}
\hline \multirow{2}{*}{ Diente } & \multicolumn{2}{|c|}{ Éxito } & \multicolumn{6}{c|}{ Fracaso } & \multicolumn{2}{c|}{ Total } \\
\cline { 2 - 12 } & Retención completa & \multicolumn{2}{|c|}{ Parcial } & \multicolumn{2}{c|}{ Perdido } & Parcial + Perdido & \multicolumn{2}{c|}{} \\
\cline { 2 - 12 } & $\mathbf{n}^{*}$ & $\%$ & $\mathbf{n}$ & $\%$ & $\mathbf{n}$ & $\%$ & $\mathbf{n} *$ & $\%$ & $\mathbf{n}$ & $\%$ \\
\hline 65 & 7 & 9.3 & 46 & 61.3 & 22 & 29.3 & 68 & 90.6 & 75 & 100 \\
\hline 75 & 23 & 30.6 & 31 & 41.3 & 21 & 28 & 52 & 69.3 & 75 & 100 \\
\hline Total & 30 & 20 & 77 & 51.4 & 43 & 28.6 & 120 & 80 & 150 & 100 \\
\hline
\end{tabular}

Prueba de Chi Cuadrado. *Éxito $p=0.0013{ }^{* *}$ Fracaso $p=0.332 \quad p=0.0022$

Tabla 3. Retención de los selladores de ionómero de vidrio según el diente sellado

\begin{tabular}{|c|c|c|c|c|c|c|c|c|c|c|}
\hline \multirow{2}{*}{ Diente } & \multicolumn{2}{|c|}{ Éxito } & \multicolumn{6}{c|}{ Fracaso } & \multicolumn{2}{c|}{ Total } \\
\cline { 2 - 12 } & \multicolumn{2}{|c|}{ Retención completa } & \multicolumn{2}{|c|}{ Parcial } & \multicolumn{2}{c|}{ Perdido } & Parcial + Perdido & \multicolumn{2}{c|}{} \\
\cline { 2 - 12 } & $\mathbf{n}^{*}$ & $\%$ & $\mathbf{n}$ & $\%$ & $\mathbf{n}$ & $\%$ & $\mathbf{n}^{* *}$ & $\%$ & $\mathbf{n}$ & $\%$ \\
\hline 55 & 8 & 10.6 & 39 & 52 & 28 & 37.3 & 67 & 89.3 & 75 & 100 \\
\hline 85 & 12 & 16 & 43 & 57.3 & 20 & 26.6 & 63 & 84 & 75 & 100 \\
\hline Total & 20 & 13.4 & 82 & 54.6 & 48 & 32 & 130 & 86.6 & 150 & 100 \\
\hline
\end{tabular}

Prueba de Chi Cuadrado. *Éxito $p=0.548{ }^{* *}$ Fracaso $p=0.314 \quad p=0.887$

Tabla 4. Retención de los selladores según grupo de tratamiento

\begin{tabular}{|c|c|c|c|c|c|c|c|c|c|c|}
\hline \multirow{3}{*}{$\begin{array}{l}\text { Grupo de } \\
\text { tratamiento }\end{array}$} & \multirow{2}{*}{\multicolumn{2}{|c|}{$\begin{array}{c}\text { Tratamiento } \\
\text { exitoso }\end{array}$}} & \multicolumn{6}{|c|}{ Fracaso } & \multirow{2}{*}{\multicolumn{2}{|c|}{ Total }} \\
\hline & & & \multicolumn{2}{|c|}{ Parcial } & \multicolumn{2}{|c|}{ Perdido } & \multicolumn{2}{|c|}{ Parcial + Perdido } & & \\
\hline & $\mathrm{n}^{*}$ & $\%$ & $\mathbf{n}$ & $\%$ & $\mathbf{N}$ & $\%$ & $\mathbf{n}^{* *}$ & $\%$ & $\mathbf{n}$ & $\%$ \\
\hline $\begin{array}{c}\text { Experimental } \\
\left(\text { KetacMolar }{ }^{\circledR}\right)\end{array}$ & 20 & 13.3 & 82 & 54.6 & 48 & 32 & 130 & 86.6 & 150 & 100 \\
\hline $\begin{array}{c}\text { Control } \\
\text { (Clinpro®) }\end{array}$ & 30 & 20 & 77 & 51.3 & 43 & 28.6 & 120 & 80 & 150 & 100 \\
\hline Total & 50 & 16.6 & 159 & 53 & 91 & 30.3 & 250 & 83.4 & 300 & 100 \\
\hline
\end{tabular}

Prueba de Chi Cuadrado. *Éxito $p=0.247{ }^{* *}$ Fracaso $p=0.698 \quad p=0.163$ 
Tabla 5. Incidencia de lesiones de caries entre los grupos experimentales y control

\begin{tabular}{|c|c|c|c|c|c|c|}
\hline \multirow{2}{*}{} & \multicolumn{2}{|c|}{ Experimental } & \multicolumn{2}{c|}{ Control } & \multicolumn{2}{c|}{ Total } \\
\cline { 2 - 7 } & $\mathbf{n}$ & $\%$ & $\mathbf{n}$ & $\%$ & $\mathbf{n}$ & $\%$ \\
\hline Con caries & 0 & 0 & 7 & 16.3 & 7 & 7.7 \\
\hline Sin caries & 48 & 100 & 36 & 83.7 & 84 & 92.3 \\
\hline Total & 48 & 100 & 43 & 100 & 91 & 100 \\
\hline
\end{tabular}

Fisher $p=0.003 \quad(p<0.05)$.

\section{Discusión}

Los selladores han demostrado ser eficaces para prevenir lesiones de caries dental en fosas y fisuras. Esta propiedad preventiva se basa en el establecimiento de una barrera física que impide que el sustrato llegue a la microflora que se encuentra en las fisuras. Sin embargo, se ha indicado que ese efecto preventivo ocurrirá mientras que el material se encuentre en el sitio donde fue aplicado ${ }^{25,26}$. Para que lo anterior ocurra, es necesario realizar una adecuada técnica de aplicación del material sellador, para que el suceso de la retención perdure en el tiempo ${ }^{27}$.

Actualmente, en el mercado se encuentran disponibles selladores de resina y de ionómero de vidrio, no obstante, los que mayormente son comercializados son a base de resina ${ }^{25}$. En este estudio, dos tipos de selladores, uno a base de resina (Clinpro® ${ }^{\circledR} 3 \mathrm{M}$ ESPE, fotopolimerizable, de baja viscosidad y liberación de fluoruro) y otro de vidrio ionomérico (Ketac Molar® 3M ESPE, convencional de alta densidad), fueron utilizados para evaluar clínicamente la retención y su efecto preventivo contra la caries en segundos molares primarios en niños de 3 a 5 años de edad.

Por otra parte, la mayoría de los estudios sobre selladores, han utilizado diseño un media - boca, en el que se tratan los dientes de un lado de la boca, mientras que los dientes contralaterales se mantienen sin tratamiento para ser utilizados como controles ${ }^{28}$. El presente estudio se realizó con un diseño de boca-dividida, donde dos segundos molares temporales recibieron un sellador a base de resina y los contralaterales, sellador de ionómero de vidrio.

Cabe resaltar, que la técnica de aplicación de los selladores de resina, es muy sensible y se encuentra influenciada por varios factores, como la presencia de placa dental en la superficie oclusal, la cooperación del paciente, el operador, y la contaminación del campo operatorio ${ }^{29}$. Un inconveniente sustancial al emplear este tipo de material, es que el procedimiento clínico es extremadamente sensible a la humedad, aunado a la presencia de la biopelícula, lo cual dificulta la efectividad del grabado ácido ${ }^{30}$. Igualmente, se ha descrito que las tasas de retención empleando aislamiento con dique de goma o rollos de algodón, son eficaces, y que el aislamiento absoluto no es necesario para la aplicación de sellantes, siempre y cuando se elimine previamente la biopelícula y se evite que la superficie grabada entre en contacto con la saliva ${ }^{31,32}$. En este estudio, se seleccionaron pacientes con los segundos molares temporales completamente erupcionados, empleando aislamiento absoluto y profi- 
laxis con piedra pómez para la aplicación de los selladores de resina, y técnica de cepillado más aislamiento relativo con rollos de algodón para la aplicación de los selladores de ionómero.

Por otro lado, los selladores de ionómero de vidrio proporcionan efecto preventivo contra las caries, además de permitir una manipulación más fácil y ausencia de grabado ácido. Este material, puede ser útil en condiciones donde no exista buen control de la humedad, en pacientes con problemas de conducta o en niños muy pequeños $^{30,33}$. Así mismo, se trata de un material biocompatible, el cual tiene un coeficiente de expansión térmica ligeramente inferior a la estructura dental; de fácil aplicación, reduce el tiempo operatorio y se adhiere adecuadamente al diente ${ }^{34}$. Estas ventajas del sellante de ionómero de vidrio permiten que sea una opción de tratamiento adecuada, para los programas de atención comunitaria.

En este estudio, posterior a 12 meses, el sellador de resina mostró retención completa de $20 \%$, retención parcial de $51.4 \%$ y $28.6 \%$ pérdida. Estos resultados concuerdan con lo reportado por Whitehurst y Soni ${ }^{35}$, quienes informaron que sólo el $18 \%$ de los segundos molares primarios se encontraban completamente sellados después de 1 año. Además, Stephen y col. ${ }^{35}$ indicaron que sólo 12 de 400 dientes quedaron completamente sellados después 1 año. Los bajos índices de retención de los selladores de resina, pueden deberse a errores en la técnica de aplicación, la no eliminación de la placa bacteriana previa a su aplicación, la presencia de restos de piedra pómez alojados en el fondo de la fisura que impiden la correcta penetración del mismo, un inadecuado diagnóstico de las fisuras a sellar, desgaste del material y / o una combinación entre los factores mencionados ${ }^{36}$.
Por otra parte, la retención observada en los molares con selladores de ionómero de vidrio a los doce meses fue de $13.3 \%$ con retención completa, parcial $54.6 \%$ y $32 \%$ con ausencia del sellador. Algunos estudios ${ }^{37}$, reportan tasas bajas de retención del sellador de ionómero de vidrio con respecto al de resina, mostrando valores de $8 \%$ y $10 \%$ de retención completa y pérdida del material hasta de un $92 \%$. Estos hallazgos pueden deberse a la inadecuada adhesión del material a la superficie del esmalte, debido a contaminación con saliva, lo que conlleva a una pérdida prematura del sellador. Así mismo, la morfología irregular de la superficie oclusal o el desgaste de la misma, puede llevar a la formación de burbujas, disminuyendo la fuerza de adhesión ${ }^{38}$.

De igual manera, habría que considerar que los materiales resinosos se adhieren al esmalte mediante técnicas de grabado ácido, que podrían proporcionar uniones mecánicas más fuertes que los enlaces moleculares producidos con los ionómeros. Por tal motivo, cuando se aplican ionómeros de vidrio como selladores en molares con fisuras poco profundas el material se desgasta rápidamente debido a la erosión y a la abrasión, lo que conlleva a una selección adecuada de los molares a ser sellados ${ }^{39}$.

En otro orden de ideas, el efecto preventivo del ionómero de vidrio frente a la caries, depende tanto de la retención como de la liberación de iones de fluoruro del material. Estos selladores han demostrado ser eficaces no solo en prevenir las desmineralizaciones antes de su inicio, sino también, deteniendo el progreso de las lesiones en sus fases más tempranas y remineralizando la estructura dental dañada ${ }^{40}$.

Se ha reportado, que la capacidad de liberación y recarga de fluoruro que presentan estos cementos puede prevenir el desarrollo de caries, 
ayudando a neutralizar el $\mathrm{pH}$ de la saliva y disminuir el número de bacterias, incluso posterior a la pérdida visible del mismo, esto se debe a pequeñas porciones residuales del sellador en el fondo de las fisuras unidas al esmalte que evitarían la desmineralización de la superficie aumentando su resistencia ${ }^{40}$. El establecimiento de un reservorio o depósito de fluoruro podría contribuir a la prevención de la enfermedad, direccionando la efectividad de los selladores de ionómero menos dependiente a su retención a largo plazo.

Dentro de este marco, los molares con pérdida del sellador de ionómero de vidrio luego de 12 meses, no manifestaron presencia de lesiones de caries dental, mientras que el grupo tratado con el sellador de resina, 7 desarrollaron la enfermedad. Estos datos nos permitirían inferir, que los ionómeros pueden ser considerados como una alternativa viable para la prevención de caries dental, más por su prolongada liberación de fluoruro que por el sellado en sí de las fisuras.

\section{Conclusiones}

La retención del sellador de resina fue superior a la del cemento de ionómero de vidrio luego de 1 año. La retención de los selladores en los dientes mandibulares fue superior a la observada en los dientes maxilares. No hubo incidencia de lesiones de caries dental en el grupo de molares sellados con pérdida del ionómero de vidrio, contrario al grupo que recibió el sellador a base de resina. Los selladores de ionómero de vidrio pueden considerarse como una alternativa para la prevención de caries dental, más por su liberación de fluoruro que por la retención del mismo.

\section{Agradecimientos}

Agradecemos a la fundación Centro Dental Inteligente (CDI), por su importante y valiosa colaboración, para el desarrollo de la presente investigación.

\section{Referencias}

1.- Irigoyen ME, Zepeda MA, Sánchez TL, Molina N. Prevalencia e incidencia de caries dental y hábitos de higiene bucal en un grupo de escolares del sur de la Ciudad de México: estudio de seguimiento longitudinal. Rev ADM 2001;52(3):98-104.

2.- Instituto Mexicano del Seguro Social. Diagnóstico de salud bucal 1990. Encuesta Epidemiológica de Salud Bucal. México: Subdirección General Médica, IMSS.1991

3.- Secretaría de Salud. Programa Nacional de Salud 2001-2006. México: SS.2006.

4.- Instituto Mexicano del Seguro Social. Programa institucional de salud bucal 2001-2006. México: IMSS; Coordinación de Salud Pública.2006.

5.- Ekstrand K. Improving Clinical Visual Detection-Potential for Caries Clinical Trials. J Dent Res.2004; C: p.67-71.

6.- Law V, Seow WK, Townsend G. Factors influencing oral colonization of mutans streptococci in young children. Aust Dent J. 2007Jun;52(2):93-100.

7.- Zambrano O, Lozano M, Arraiz N, Rivera L, Aguilera L, Chourio G. Tratamiento ultraconservador en la remoción de caries dental: evaluación microbiológica. Rev Venez Invest Odont IADR 2013;1(1):3-15.

8.- American academy of pediatric dentistry. Guideline on Behavior Guidance for the Pediatric Restorative Dentistry. 2011; Vol 33, No. 6.

9.- Aguilar FG, Drubi-Filho B, Casemiro LA, Watanabe M, Pires-de-Souza F. Retention and penetration of a conventional resin-based sealant and a photochromatic flowable composite resin placed on occlusal pits and fissures. J Indian Soc Pedod Prev Dent 2007;25:169-73. 
10.- Welbury R, Raadal M, Lygidakis N. EAPD guidelines for the use of pit and fissure sealants. European journal of paediatric dentistry. 2004;3/ p.179-184.

11.- Oulis C, Berdouses E, Mamai - Homata E, Polychoronopoulou A. Prevalence of sealants in relation to dental caries on the permanent molars of 12 and 15 year old Greek adolescents. A national Pathfinder survey. BMC Public Health. 2011;Vol11:100

12.- Beauchamp J, Caufield P, Crall J, Donly K, Feigal R, Gooch B, Ismail A, Kohn W, Siegal M, Simonsen R. Evidence-Based Clinical Recommendations for the Use of Pit-and-Fissure Sealants: A Report of the American Dental Association Council on Scientific Affairs. J Am Dent Assoc. 2008;139; 257-268.

13.- Kavaloglu S, Sandalli N. Compressive Strength, Surface Roughness, Fluoride Release and Recharge of FourNew Fluoride-releasing Fissure Sealants. Dental Materials Journal. 2007;26(3): 335-341.

14.- Ahovuo-Saloranta, Hiiri A, Nordbland A, Makela M, Worthington HV. Pit and fissure sealants for preventing dental decay in the permanent teeth of children and adolescents. Cochrane Database Syst Rev. 2010,8(4):CD001830.

15.- Azarpazhooh A, Main PA. Pit and fissure sealants in the prevention of dental caries in children and adolescents: a systematic review. J Can Dent Assoc.2008 Mar;74(2):171-7.

16.- Simonsen RJ. Pit and Fissure sealant: review of literature. Pediatric Dent.2002 Sep-Oct;24(5):393-414.

17.- Salar DV., García-Godoy F., Flaitz CM., Hicks MJ. Potential inhibition of demineralization in vitro by fluoride-releasing sealants. J Am Dent Assoc.2007 Apr;138(4):502-6.

18.- Trairatvorakul C., Kladkaew S., Songsiripradabboon S. Active Management of Incipient Caries and Choice of Materials. J Dent Res.2008 Mar;87(3):228-232.

19.- Kantovitz KR., Pascon FM., Correr GM., Borges AF., Uchoa MN., Puppin-Rontani RM. Inhibition of mineral loss at the enamel/sealant interface of fissures sealed with fluoride- and non-fluoride containing dental materials in vitro. Acta Odontol Scand.2006 Nov;64(6):376-83.

20.- Beiruti N., Frencken JE., van't Hof MA., Taifour D., van Palenstein Helderman WH. Caries-preventive effect of a onetime application of composite resin and glass ionomer sealants after 5 years. Caries Res.2006;40(1):52-9.

21.- Beiruti N., Frencken JE., van 't Hof MA., van Palenstein Helderman WH. Caries-preventive effect of resin-based and glass ionomer sealants over time: a systematic review. Community Dent Oral Epidemiol.2006 Dec; 34(6):403-9.

22.- International Caries Detection \& Assessment System Coordinating Committee. The International Caries Detection and Assessment System (ICDAS II at June 2005). 2005. Disponible en: www.icdas.org.

23.- Declaración de Helsinki: principios éticos para la investigación médica sobre sujetos humanos. Análisis de la $5^{a}$ Reforma, aprobada por la Asamblea General, de la Asociación Médica Mundial en octubre del año 2000, en Edimburgo, Respecto del texto aprobado en Somerset West (Sudáfrica) en octubre de 1996. Acta Bioética.2000;VI,nº 2

24.- García-Godoy F. Retention of a light-cured fissure sealant (Helioseal) in a tropical environment after 12 months. Clin Prev Dent.1986;8:11-3.

25.- Luengo J, Zambrano O, Rivera L. Sellado de lesiones de caries dental no cavitadas: Ensayo clínico aleatorio controlado. Rev. odontopediatr. Latinoam.2013;Vol.3,\#2,p.45-57.

26.- Aranda M, Garcia-Godoy F. Clinical evaluation of the retention and wear of a ligth-cured pit and fissure glass ionomer sealant. J Clin Pediatr Dent.1995;19:273-7.

27.- Pope B, Garcia-Godoy F, Summitt J, Chan D. Effectiveness of oclusal fissure cleansing methods and selant micromorphology. ASDC J Dent Child.1996;63:175-80.

28.- Mertz-Fairhurst EJ, Della-Giustina VE, Brooks JE, Williams JE, Fairhurst CW. A comparative study of two pit and fissure sealants: Results after 4 1/2years in Augusta, Ga. J Am Dent Assoc.1981;103:235-8.

29.- Karlzen G, van Dijken J. A three year follow up of glass ionomer cement and resin fissure sealants. ASDC J Dent Child.1995;62:108-10.

30.- Raadal M, Utkilen A, Nilsen O. Fissure sealing with a ligth-cured resin reinforced glass-ionomer cement (vitrebond) compared with a resin sealant. Int J Pediatr Dent.1995;6:235-9.

31.- Albani F., Ballesio I., Campanella V., Marzo G. Pit and fissure sealants: Results at five and 10 years. Eur J Paediatr Dent.2005;6:61-5. 
32.- Muller-Bolla M., Lupi-Pégurier L., Tardieu C., Velly AM., Antomarchi C. Retention of resin-based pit and fissure sealants: A systematic review. Community Dent Oral Epidemiol.2006 Oct;34(5):321-36.

33.- Turksel C, Colak h. Rural dentistry: Is it an imagination or obligation in community dental health education?. Niger Med J. 2012 Jan-Mar;53(1):1-8.ural dentistry: Is it an imagination or obligation in community dental health education?ural dentistry: Is it an imagination or obligation in community dental health education?ural dentistry: Is it an imagination or obligation in community dental health education?

34.- Yip HK, Smales RJ. Glass ionomer cements used as fissure sealants with the atraumatic restorative treatment (ART) approach: Review of literature. Int Dent J.2002;52:67-70.

35.- Ripa LW. Occlusal sealants: Rationale and review of clinical trials. Int Dent J 1980;30:127-39.

36.- Messer LB, Calache H, Morgan MV. The retention of pit and fissure sealants placed in primary school children by Dental Health Services, Victoria. Aust Dent J.1997;42:233-9.

37.- Poulsen S, Beiruti N, Sadat N. A comparison of retention and the effect on caries of fissure sealing with a glass-ionomer and a resin-based sealant. Community Dent Oral Epidemiol.2001;29: 298-301.

38.- Mejàre I, Mjör IA. Glass ionomer and resin-based fissure sealants: A clinical study. Scand J Dent Res.1990;98:345-50.

39.- Wilson AD, McLean JW. Glass-Ionomer Cement. Quintessence Publishing Co.1988.

40.- Valencia J. Ionómeros de vidrio remineralizantes. Una alternativa de tratamiento preventivo o terapéutico. Rev. ADM. $2011 ; 68(5): 258-265$.

Recibido: 14-02-2014

Aceptado: 10-07-2014

Correspondencia: Carretera la Bufa S/N, colonia centro, Zacatecas, Zac, México. Código Postal: 98000. Especialidad en Odontopediatría. Unidad Académica de Odontología. Universidad Autónoma de Zacatecas. Zacatecas, México.

Teléfono: +52-492-9229650,Email: jluengofereira@gmail.com 